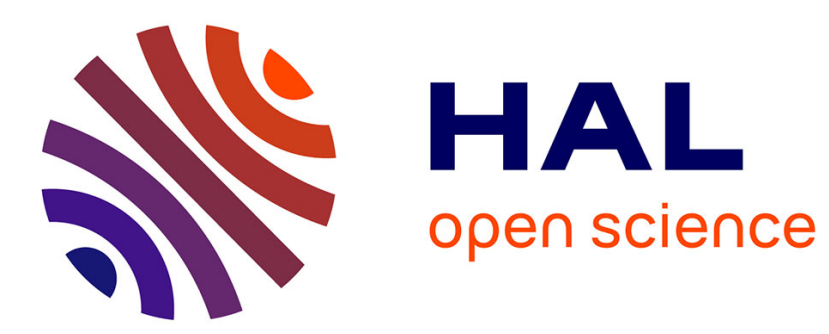

\title{
Electrochemical attachment of a conjugated amino-ferrocifen complex onto carbon and metal surfaces
}

Olivier Buriez, Eric Labbé, Pascal Pigeon, Gérard Jaouen, Christian Amatore

\section{To cite this version:}

Olivier Buriez, Eric Labbé, Pascal Pigeon, Gérard Jaouen, Christian Amatore. Electrochemical attachment of a conjugated amino-ferrocifen complex onto carbon and metal surfaces. Journal of electroanalytical chemistry and interfacial electrochemistry, 2008, 619, pp.169-175. 10.1016/j.jelechem.2008.04.012 . hal-01230398

\section{HAL Id: hal-01230398 \\ https://hal.science/hal-01230398}

Submitted on 27 Nov 2019

HAL is a multi-disciplinary open access archive for the deposit and dissemination of scientific research documents, whether they are published or not. The documents may come from teaching and research institutions in France or abroad, or from public or private research centers.
L'archive ouverte pluridisciplinaire HAL, est destinée au dépôt et à la diffusion de documents scientifiques de niveau recherche, publiés ou non, émanant des établissements d'enseignement et de recherche français ou étrangers, des laboratoires publics ou privés. 


\title{
Electrochemical attachment of a conjugated amino-ferrocifen complex onto carbon and metal surfaces
}

\author{
Olivier Buriez ${ }^{\mathrm{a}}$, Eric Labbé ${ }^{\mathrm{a}}$, Pascal Pigeon ${ }^{\mathrm{b}}$, Gérard Jaouen ${ }^{\mathrm{b}}$, Christian Amatore ${ }^{\mathrm{a}^{*}}$ \\ a Ecole Normale Supérieure, Département de Chimie, UMR CNRS-ENS-UPMC 8640 "PASTEUR", 24 Rue \\ Lhomond, Paris Cedex 05 F-75231, France \\ ${ }^{\mathrm{b}}$ Laboratoire de Chimie Organométallique, UMR CNRS 7576, Ecole Nationale Supérieure de Chimie de Paris, \\ 11 Rue Pierre et Marie Curie, 75231 Paris 05, France
}

* Corresponding authors. Tel.: +33 (1) $4432 \quad 3388$; fax: +33 (1) $4432 \quad 3863$. E-mail addresses:
olivier.buriez@ens.fr (O. Buriez), christian.amatore@ens.fr (C. Amatore).

Keywords: Modified electrode; Ferrocene; Amine; Electron transfer; Mechanism

\begin{abstract}
The attachment of a $\pi$-conjugated amino-ferrocifen complex was electrochemically achieved either by direct oxidation of the amino group or via the oxidation of the ferrocene moiety. In the first case, the modification consists in oxidizing, at $+0.70 \mathrm{~V} / \mathrm{SCE}$, the amino moiety to its radical cation, which upon deprotonation from the amino group, yields an aminyl radical that may add onto the electrode surface. Alternatively, it is demonstrated that the amine moiety can be indirectly oxidized through an intra-molecular electron transfer from the amino moiety to the ferrocenyl group after oxidation of the ferrocene part at $+0.40 \mathrm{~V}$. This can occur thanks to the conjugated $\pi$ system of the complex. More importantly, it is demonstrated that the covalent attachment of the complex can be achieved on glassy carbon, gold, and platinum surfaces whatever the approach used. The possible mechanisms for the covalent attachment are discussed. Interestingly, it is also shown that the amino-ferrocene compound adsorbs very well likely via $\pi$ stacking between grafted and non-grafted molecules. Nevertheless, the adsorbed molecules could be easily removed after passing the electrode in an ultrasonic bath.
\end{abstract}


The electrode coverage was determined under various conditions by integration of the corresponding voltammograms.

\section{Introduction}

The immobilization of organic layers and conductive molecules onto carbon and metal surfaces is of increasing interest for applications including molecular electronics, sensors, catalysis, and electrocatalysis.

In this context, two main routes are generally used for the attachment of molecules onto surfaces. The self-assembled monolayer (SAM) of thiolated molecules on gold and some other metals such as platinum, silver, copper and mercury is the most popular procedure since it leads to well organized monolayers thanks to the weak bond between sulfur and metal [1]. Another approach consists to covalently attach organic molecules by electrochemical oxidation or reduction of the latter. This technique leads to stronger bonding than those obtained with adsorbed compounds, but the molecule layers are less organized. Presently, the most commonly used electrochemical procedures for derivatizing carbon and metal surfaces are based on the electrochemical oxidation of amine-containing compounds [2], [3] or the electrochemical reduction of aryldiazonium salts [4], [5], [6], [7].

In the first method, the attachment of the amino group was initially assigned to the radicalcation formed upon oxidation of the amine, but more recent investigations indicated that it is the radical obtained after deprotonation of the radical-cation which actually reacts with the electrode surface [8]. In general, the attachment of the amino group obtained by this procedure is evidenced through the observation of the electrochemical signal of redox groups such as nitro [2], [3], [8], anthracene, anthraquinone [2], or hydroquinone [9]. Interestingly, it was demonstrated that the surface concentration of amino groups was lower with secondary amines than with primary ones whereas tertiary amines hardly graft at all [3], [8]. This behaviour is attributed to a strong steric effect whereby bulky substituents on the nitrogen atom hinder accessibility of the reactive amine radical to surface binding sites.

The second method consists in the electrochemical reduction of aryl diazonium salts that leads to the covalent attachment of the corresponding aromatic radicals. Diazonium salts are generally prepared from aromatic amines, but recently it has been shown that they can be generated in situ from the corresponding amine with $\mathrm{NaNO}_{2}$ in aqueous $\mathrm{HCl}$ [5]. As for the 
first procedure, a large variety of materials such as carbon [6], [10], [11], [12], semiconductors [13], [14], [15], and metals [16], [17] can be modified by this method.

Interestingly, recent works have showed the possibility to derivatize surfaces without electrochemistry, by simple immersion of the surface in a diazonium solution [11], [15], [18]. Similarly, spontaneous attachment of amines to carbon and metallic surfaces has been very recently achieved [19].

On the other hand, several approaches have been developed to attach metallic species and organometallic complexes to electrode surfaces through organic layers. Very recently, it has been shown that copper(II) cations can be supported on carbon surfaces through electrostatic interactions with previously grafted phenylsulfonate groups [20]. Another example concerns the fabrication of mono- and -multilayer films of polyoxometalates also based on electrostatic attraction with covalently grafted 4-aminobenzoic acid. The latter which is negatively charged at high $\mathrm{pH}$ value has been used as a charged precursor substrate to assemble polyoxometalates containing multilayer films by layer-by-layer assembling technique [21].

Alternatively, some works have been devoted to the covalent attachment of organometallic complexes such as ferrocene. Recently, the reactivity of 4-bromophenyl modified glassy carbon electrode in the presence of 4-aminophenyl ferrocene has been reported [22]. However, even if the presence of ferrocene moieties at the electrode was demonstrated by cyclic voltammetry and X-ray photoelectron spectroscopy, no definitive conclusion could be made on the attachment of the ferrocene moiety. Its presence at the electrode surface could indeed be explained either by the nucleophilic displacement of bromine of the 4-bromophenyl grafted groups by the amine of the ferrocene derivative, or $\pi$ stacking between the phenyl rings of the ferrocene derivative and the grafted phenyl group.

More recently, the covalent attachment of ferrocenemethylamine has been achieved on a glassy carbon electrode in a stepwise process. The electrochemical reduction of 4carboxyphenyl diazonium salts was first performed to yield a stable monolayer to which ferrocenemethylamine could be then covalently attached via a condensation reaction [23]. In this case the modified electrode was fully characterized and the covalent attachment of the ferrocene group was demonstrated.

In the present work, it is demonstrated that the one step covalent attachment of a $\pi$-conjugated amino-ferrocifen compound (1) (1-(4-aminophenyl)-1-phenyl-2-ferrocenylbut-1-ene Scheme 1) to glassy carbon and metal surfaces ( $\mathrm{Au}$ and $\mathrm{Pt}$ ), has been successfully achieved. 


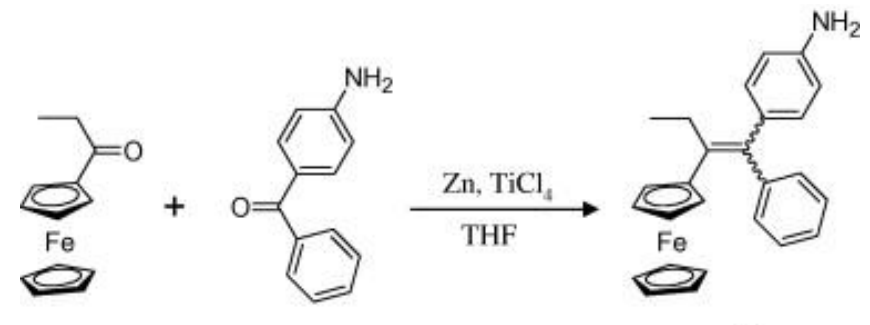

(1)

Scheme 1. Preparation of the aminoferrocifen complex (1).

This was realized either by direct or indirect electrochemical oxidation of the amino group in the presence of 2,4,6-trimethylpyridine (collidine) as a base. In the first case, the amino moiety was oxidized into the corresponding cation radical which, upon deprotonation, yields an aminyl radical that adds onto the electrode surface. Alternatively, it is demonstrated that the amine moiety can be indirectly oxidized through an intra-molecular electron transfer from the amino moiety to the ferrocenyl group after oxidation of the ferrocene part. This can occur thanks to the conjugated $\pi$ system, and allows the amine to oxidize at a lower potential value.

These results are of high importance since such ferrocifen complexes possess biological activities against breast cancer cell lines [24]. Their immobilization will be therefore useful to study the environment effects of these compounds in defined molecular architectures.

\section{Experimental}

\subsection{Chemicals}

Lithium perchlorate (Aldrich) was used as the supporting electrolyte. Methanol (Acros) and 2,4,6-trimethylpyridine (collidine; Acros) were used as received.

The ferrocifen complex was synthesised by McMurry cross-coupling of the appropriate ketones as follows (Scheme 1).

Synthesis of 1-(4-aminophenyl)-1-phenyl-2-ferrocenylbut-1-ene (1): Titanium tetrachloride (5.5 mL, $50 \mathrm{mmol})$ was added dropwise under argon atmosphere to a suspension of zinc powder $(5.2 \mathrm{~g}, 80 \mathrm{mmol})$ in $40 \mathrm{~mL}$ of THF at $0-20{ }^{\circ} \mathrm{C}$. The obtained mixture was heated at reflux for $2 \mathrm{~h}$. A solution was prepared by dissolving propionylferrocene ( $2.42 \mathrm{~g}, 10 \mathrm{mmol})$ 
[25] and 4-aminobenzophenone (3.94 g, $20 \mathrm{mmol})$ in $30 \mathrm{~mL}$ of THF. This latter solution was added dropwise in 20 min to the refluxing mixture, then the heating was continued for $48 \mathrm{~h}$. After cooling to room temperature, the mixture was stirred with water and dichloromethane and was acidified with dilute hydrochloric acid until the black suspension disappeared, then was decanted. The aqueous layer was extracted twice with dichloromethane and the combination of organic layers was washed with water then was dried over magnesium sulfate. After concentration under reduced pressure, the crude product was chromatographed on silica gel with dichloromethane as eluent to give a mixture that was recrystallized from ether/pentane solution to give a 55/45 mixture of $\mathrm{Z}+\mathrm{E}$ isomers with a yield of $26 \%$. ${ }^{1} \mathrm{H} \mathrm{NMR}$ $\left(300 \mathrm{MHz}, \mathrm{CDCl}_{3}\right) \delta: 1.01$ and $1.04\left(\mathrm{t}, 3 \mathrm{H}, J=7.5 \mathrm{~Hz}, \mathrm{CH}_{3}\right), 2.54$ and 2.60 (q, 2H, $J=7.5$ $\mathrm{Hz}, \mathrm{CH}_{2}$ ), 3.85 and 3.96 (t, $\left.2 \mathrm{H}, J=1.9 \mathrm{~Hz}, \mathrm{C}_{5} \mathrm{H}_{4}\right), 4.03$ and 4.07 (t, $2 \mathrm{H}, J=1.9 \mathrm{~Hz}, \mathrm{C}_{5} \mathrm{H}_{4}$ ), 4.09 and $4.10\left(\mathrm{~s}, 5 \mathrm{H}, \mathrm{C}_{5} \mathrm{H}_{5}\right), 6.54$ and $6.65\left(\mathrm{~d}, 2 \mathrm{H}, J=8.5 \mathrm{~Hz}, \mathrm{C}_{6} \mathrm{H}_{4}\right), 6.85$ and $7.00(\mathrm{~d}, 2 \mathrm{H}, J$ $\left.=8.5 \mathrm{~Hz}, \mathrm{C}_{6} \mathrm{H}_{4}\right), 7.17-7.31\left(\mathrm{~m}, 5 \mathrm{H}, \mathrm{C}_{6} \mathrm{H}_{5}\right) .{ }^{13} \mathrm{C} \mathrm{NMR}\left(75 \mathrm{MHz}, \mathrm{CDCl}_{3}\right) \delta: 12.9$ and 14.5 $\left(\mathrm{CH}_{3}\right), 26.8$ and $28.7\left(\mathrm{CH}_{2}\right), 66.9\left(\mathrm{C}_{5} \mathrm{H}_{4}\right), 68.2\left(\mathrm{C}_{5} \mathrm{H}_{5}\right), 68.3\left(\mathrm{C}_{5} \mathrm{H}_{4}\right), 86.0\left(\mathrm{C} \mathrm{C}_{5} \mathrm{H}_{4}\right), 114.0(2$ $\mathrm{CH}), 124.9(\mathrm{CH}), 127.0$ and 127.1(2 CH), 128.3 and $128.9(2 \mathrm{CH}), 129.3$ and $129.8(2 \mathrm{CH})$, 134.2 (C), 135.3 (C), 137.0 (C), 143.5 (C), 144.0 (C). IR ( $\left.\mathrm{KBr}, v \mathrm{~cm}^{-1}\right)$ : 3345, 3387, 3433, $3469\left(\mathrm{NH}_{2}\right), 2872,2928,2964,3021,3047,3088,3206\left(\mathrm{CH}_{2}, \mathrm{CH}_{3}\right)$. MS (EI, $\left.70 \mathrm{eV}\right) \mathrm{m} / z: 407$ $[\mathrm{M}]^{+}, 378[\mathrm{M}-\mathrm{Et}]^{+}, 342[\mathrm{M}-\mathrm{Cp}]^{+}, 121[\mathrm{CpFe}]^{+}$. HRMS (EI, $70 \mathrm{eV}, \mathrm{C}_{26} \mathrm{H}_{25} \mathrm{FeN}: \mathrm{M}^{+}$) calcd: 407.1337, found: 407.1327. Anal. Calcd for $\mathrm{C}_{26} \mathrm{H}_{25} \mathrm{FeN}$ : C, 76.66; H, 6.18; N, 3.43. Found: C, 76.27; H, 6.09; N, 3.51 .

\subsection{Instrumentation}

Cyclic voltammetry experiments were performed at room temperature under an argon atmosphere in a three electrode cell using an Autolab potentiostat. The reference electrode was an SCE (Tacussel), which was separated from the solution by a bridge compartment filled with the same solvent/supporting electrolyte solution used in the cell. The counter electrode was a gold wire. The glassy carbon (1 mm diameter, Goodfellow), the platinum $(0.5 \mathrm{~mm}$ diameter, Goodfellow), and the gold (0.5 mm diameter, Goodfellow) working electrodes were home-made. 


\subsection{Procedure}

The modification of the glassy carbon, $\mathrm{Au}$, and Pt, working electrodes was as follows: micro controlled-potential electrolyses were performed in $\mathrm{MeOH}+\mathrm{LiClO}_{4}(0.1 \mathrm{M})$ in the presence of both (1) $(5.80 \mathrm{mM})$ and collidine $(29 \mathrm{mM})$ for $5 \mathrm{~min}$ at $+0.70 \mathrm{~V}$ and $+0.40 \mathrm{~V}$. After the electrolyses the electrodes were thoroughly rinsed with methanol and ultrasonicated for 10 $\min$ in $\mathrm{MeOH}$ when mentioned.

\section{Electrochemical modification of glassy carbon and metal electrodes with an amino-ferrocene containing compound}

\subsection{Attachment of the organometallic complex (1) via the oxidation of the amine moiety}

In methanol, the cyclic voltammogram of complex (1) exhibits two successive oxidation waves $\mathrm{O}_{1}$ and $\mathrm{O}_{2}$ located at $+0.38 \mathrm{~V}$ and $+0.67 \mathrm{~V}$. These waves are assigned to the oxidation of the ferrocene and the amino groups into the corresponding ferrocenium and amino cationradical species, respectively. On the cyclic voltammetry time-scale, the ferrocenium species appears more stable than the electrogenerated amino cation-radical in agreement with a higher reversibility in the former case (Fig. 1). Interestingly, after the first oxidation, the delocalization of the single electron is almost not observable as evidenced by the small change in the oxidation potential of the ferrocene moiety (compare $+0.38 \mathrm{~V}$ for (1) with +0.42 $\mathrm{V}$ for ferrocene).

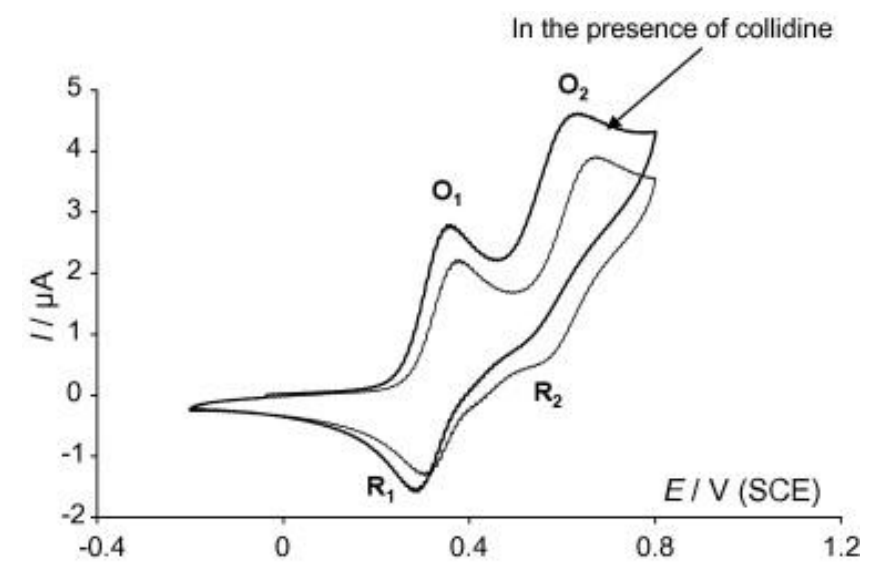

Fig. 1. Cyclic voltammograms of $(\mathbf{1})(1 \mathrm{mM})$ in $\mathrm{MeOH}+\mathrm{LiClO}_{4}(0.1 \mathrm{M})$ recorded at a bare glassy carbon electrode ( $1 \mathrm{~mm}$ diameter) at $100 \mathrm{mV} \mathrm{s}^{-1}$ in the absence and the presence of collidine (50 equivs.). 
In the presence of 2,4,6-trimethylpyridine (collidine) as a base, the redox system $\mathrm{O}_{1} / \mathrm{R}_{1}$ was slightly shifted towards more positive potential values, but remained fully reversible. As observed in the presence of pyridine with some similar hydroxy-ferrocifen complexes, we could have expected an intra-molecular electron transfer, through the conjugated $\pi$ system, from the amino group to the electrogenerated ferrocenium moiety with regeneration of the starting neutral ferrocene group and production of a cation radical amino group, as depicted in Scheme 2 [26]. However, in such a case, the reversibility of $\mathrm{O}_{1}$ should have decreased or even disappeared for a fast process. In the present case, this suggests that the intra-molecular electron transfer is too slow to be observed at the cyclic voltammetry time-scale even in the presence of collidine which is a stronger base than pyridine ( $\mathrm{pKa}=7.4$ vs. 5.2 for pyridine) demonstrating the high stability of $\left(\mathbf{1}^{+}\right)$under these conditions.

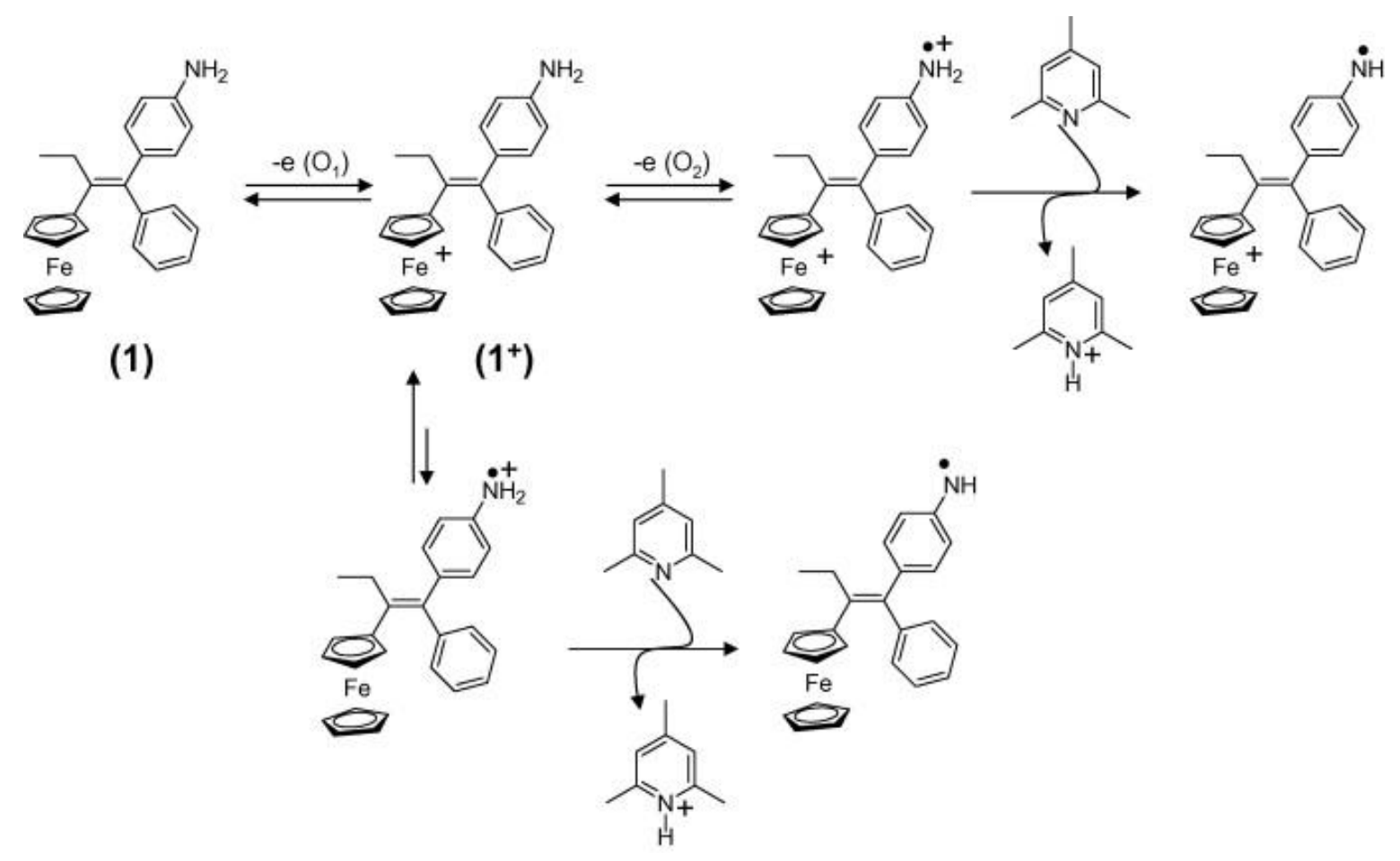

Scheme 2.

Nevertheless, the direct electrochemical oxidation of the amino group was easily achieved at the level of the oxidation wave $\mathrm{O}_{2}$. At this potential value, the two redox systems (ferrocene and amine) are both under their oxidized forms. As already reported, the presence of a base 
generally facilitates the deprotonation of the electrogenerated amino radical cations producing iminyl radicals [3], [8], [19], [21]. A similar process very likely occurs in the present case in agreement with the slight shift of $\mathrm{O}_{2}$ and the loss of its reversibility (Fig. 1 and Scheme 2).

More interestingly, when the potential was repeatedly scanned, the wave $\mathrm{O}_{2}$ gradually diminished whereas the system $\mathrm{O}_{1} / \mathrm{R}_{1}$ was quite-unaffected (Fig. 2). Importantly, this was not observed in the absence of collidine. Moreover, $\mathrm{O}_{2}$ could be recovered only after polishing the electrode. By analogy with some other reported works this result suggests the formation of a coating on the electrode surface via the aminyl radical which could react onto the carbon surface [2], [9], [21].

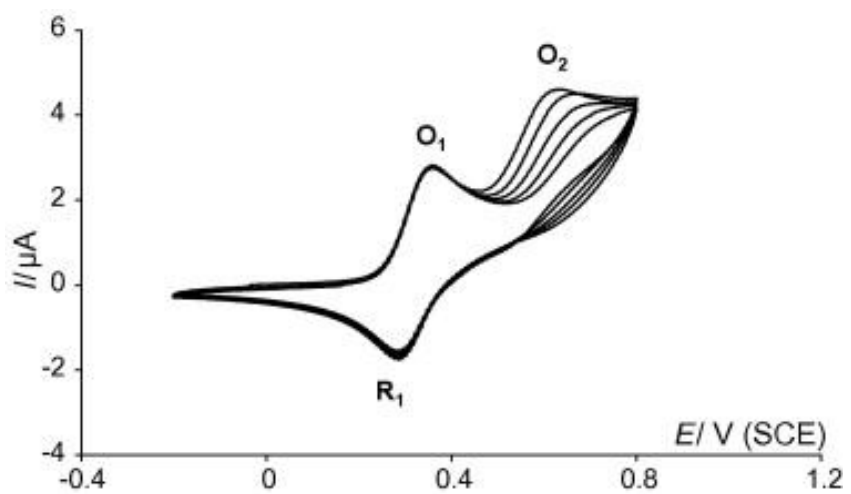

Fig. 2. Five successive cyclic voltammograms of complex (1) $(1 \mathrm{mM})$ in $\mathrm{MeOH}+\mathrm{LiClO}_{4}(0.1 \mathrm{M})$ recorded at a glassy carbon electrode ( $1 \mathrm{~mm}$ diameter) at $100 \mathrm{mV} \mathrm{s}^{-1}$ in the presence of collidine (50 equivs.) and obtained without polishing the electrode.

This result prompted us to prepare a glassy carbon electrode at the surface of which the complex (1) would be covalently attached. This was realized by performing a "micro" preparative electrolysis of compound (1) in the presence of 5 equivalents of collidine, for 5 $\min$ at $+0.70 \mathrm{~V}$, i.e. to the potential value at which the amino moiety is oxidized. Fig. 3 shows the cyclic voltammograms obtained before and after the electrolysis. 


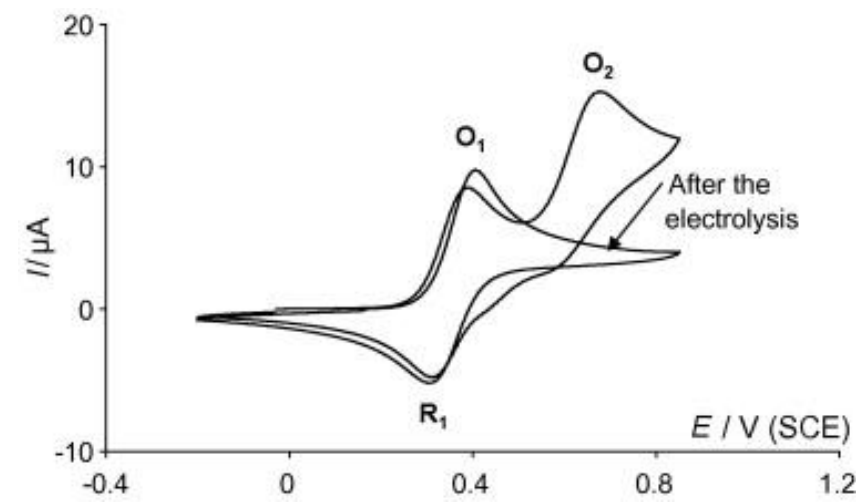

Fig. 3. Cyclic voltammograms of complex (1) $(5.80 \mathrm{mM})$ in $\mathrm{MeOH}+\mathrm{LiClO}_{4}(0.1 \mathrm{M})$ recorded at a glassy carbon electrode ( $1 \mathrm{~mm}$ diameter) at $100 \mathrm{mV} \mathrm{s}^{-1}$ in the presence of collidine (5 equivs.), before and after the controlled-potential electrolysis at $\mathrm{E}=+0.70 \mathrm{~V}$.

As expected, and in agreement with Fig. 2, the reversible oxidation of the ferrocene moiety was still observed at the end of the electrolysis, whereas $\mathrm{O}_{2}$ totally vanished indicating that oxidation of additional amino groups could no longer be observed. This means that the electrode was completely blocked towards the oxidation of additional amino groups possibly because the entire electrode surface was grafted after the electrolysis. Yet, after the electrolysis, the first redox process remained characteristic of a diffusional process. This may be due to either a low efficiency of the grafting reaction or a too large electrolysis duration time. In the latter case, unwelcome oxidation processes may lead to soluble degradation products of the amine after formation of the layer. In order to highlight a possible adsorption phenomenon on the electrode surface, that could be masked by the buffered solution, the electrode was thoroughly rinsed with methanol and transferred in another electrochemical cell containing only the solvent $(\mathrm{MeOH})$ and the supporting electrolyte $\left(\mathrm{LiClO}_{4}\right)$. The cyclic voltammogram obtained under these new conditions is shown in Fig. 4. 


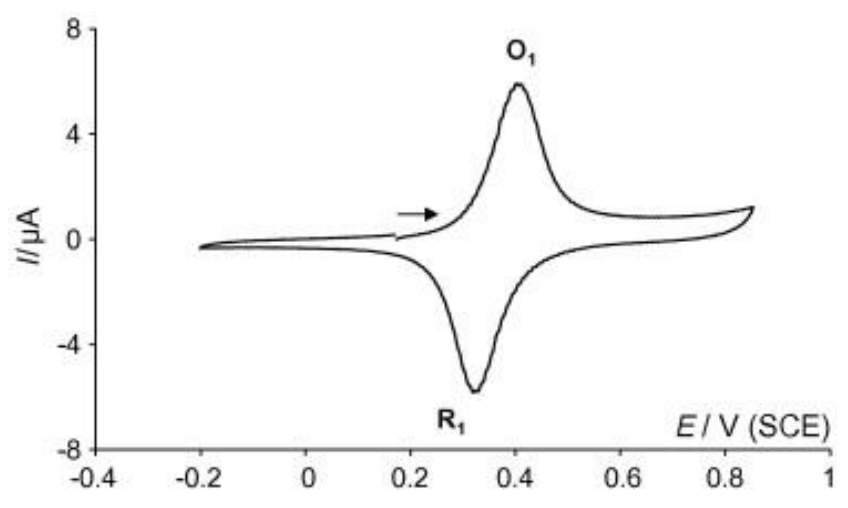

Fig. 4. Cyclic voltammogram performed in $\mathrm{MeOH}+\mathrm{LiClO}_{4}(0.1 \mathrm{M})$ with the modified working glassy carbon electrode $(1 \mathrm{~mm}$ diameter) obtained after the controlled-potential electrolysis $(\mathrm{E}=+0.70 \mathrm{~V})$. Sweep rate is 500 $\mathrm{mVs}-1$.

Interestingly, the signature of the ferrocene/ferrocenium system was still present, but the shape of the voltammogram clearly indicated the presence of adsorbed species at the electrode surface. Besides, the peak currents of both $\mathrm{O}_{1}$ and $\mathrm{R}_{1}$ were found to be proportional to the scan rate. Importantly, the voltammogram was strictly unchanged even after performing 10 cycles, indicating the irreversible character of the grafting. More importantly, the peak intensity of $\mathrm{O}_{1}$ decreased, by about a factor three, after rinsing the electrode in methanol in an ultrasonic bath for $10 \mathrm{~min}$, but remained constant upon further sonication. This result clearly demonstrates that the major part of the complex (1) was adsorbed whereas another part was strongly grafted at the electrode surface. Besides, the covalently attached molecules could only be removed by mechanical polishing. Another likely explanation may be related to the presence of weakness introduced onto the carbon surface by the grafting. Indeed, a covalent grafting is expected to lead to several transformations of the surface carbon atoms binding energies with their neighbors. Thus, under energetic sonication, some parts of the superficial modified carbon layer may be expelled. Interestingly, negligible adsorption was observed when the electrode was dipped for 5 min without any electrochemical induction in a solution containing the complex (1), showing that (1) underwent adsorption most likely according to $\pi$ stacking phenomena between grafted and un-grafted molecules [27], [28].

The electrode coverage was measured by integration of the cyclic voltammogram and was found to be $15 \times 10^{-10}$ and $5 \times 10^{-10} \mathrm{~mol} \mathrm{~cm}{ }^{-2}$ before and after 20 min sonication, respectively, in agreement with our qualitative results. Importantly, the same values were obtained from both the cathodic and the anodic peaks confirming the stability of the grafted molecules and in agreement with an immobilized redox system. 
Note that the value obtained after sonication is slightly higher than those reported about attainable surface coverage by oxidation of amines on glassy carbon surfaces [3], [8], [19]. This is likely due to the roughness of our glassy carbon electrode that contributes to increase the available surface with respect to the apparent geometrical surface.

Moreover, it can be pointed out that the cyclic voltammogram of the ferrocene moiety shows non-ideal behavior [1] with respect to peak separation at slow scan rates $\left(\Delta E_{\mathrm{p}}=60 \mathrm{mV}\right.$ rather than the ideal $\Delta E_{\mathrm{p}}=0 \mathrm{mV}$ ) and the full width half maximum (roughly $110 \mathrm{mV}$ rather than the ideal $E_{\mathrm{FWHM}}=90.6 \mathrm{mV} / n$ where $n=1$ in this case). This can be assigned to strong interactions between the redox centers which are highly concentrated at the electrode surface [29], [30].

As previously mentioned, the electrolysis performed at the potential value of wave $\mathrm{O}_{2}$ leads to the oxidation of the amino group but also to the ferrocene moiety since the latter is oxidized at a lower potential value. However, the cyclic voltammogram obtained, at the end of the electrolysis, from the open circuit potential exhibits an anodic current instead of a cathodic one, indicating that the electrogenerated ferrocenium species was recovered under its reduced form. Actually, the grafted molecule is most likely under the ferrocenium form in a first time (Scheme 3). But, in a second time, an intra-molecular electron transfer cannot be excluded, between the amino and the ferrocenium moieties. Besides, this process could be facilitated in the presence of a base since this would help the deprotonation of the amino group (the acidity of which being possibly increased after grafting to the electrode surface). Finally, the resulting amino radical could either add on the electrode surface or lead to the quinone imine species (Scheme 3) similarly to what was observed with hydroxy-ferrocifen complexes [26]. The final radical species could therefore undergo a further oxidation and deprotonation.

In conclusion, all these results clearly demonstrate that the amino-ferrocene complex (1) can be easily and covalently attached to the glassy carbon electrode surfaces via direct electrochemical oxidation of the amine moiety.

The successful grafting onto glassy carbon electrode prompted us to try and to covalently attach the amino-ferrocene complex at the surface of metal electrodes such as gold and platinum. The results obtained under these new conditions were identical to those observed on glassy carbon electrodes. Typical voltammograms obtained after electrolyses at the potential of $\mathrm{O}_{2}$ and transferring the electrodes $(\mathrm{Au}$ and $\mathrm{Pt}$ ) in another electrochemical cell containing only the solvent and supporting electrolyte are shown in Fig. 5. 

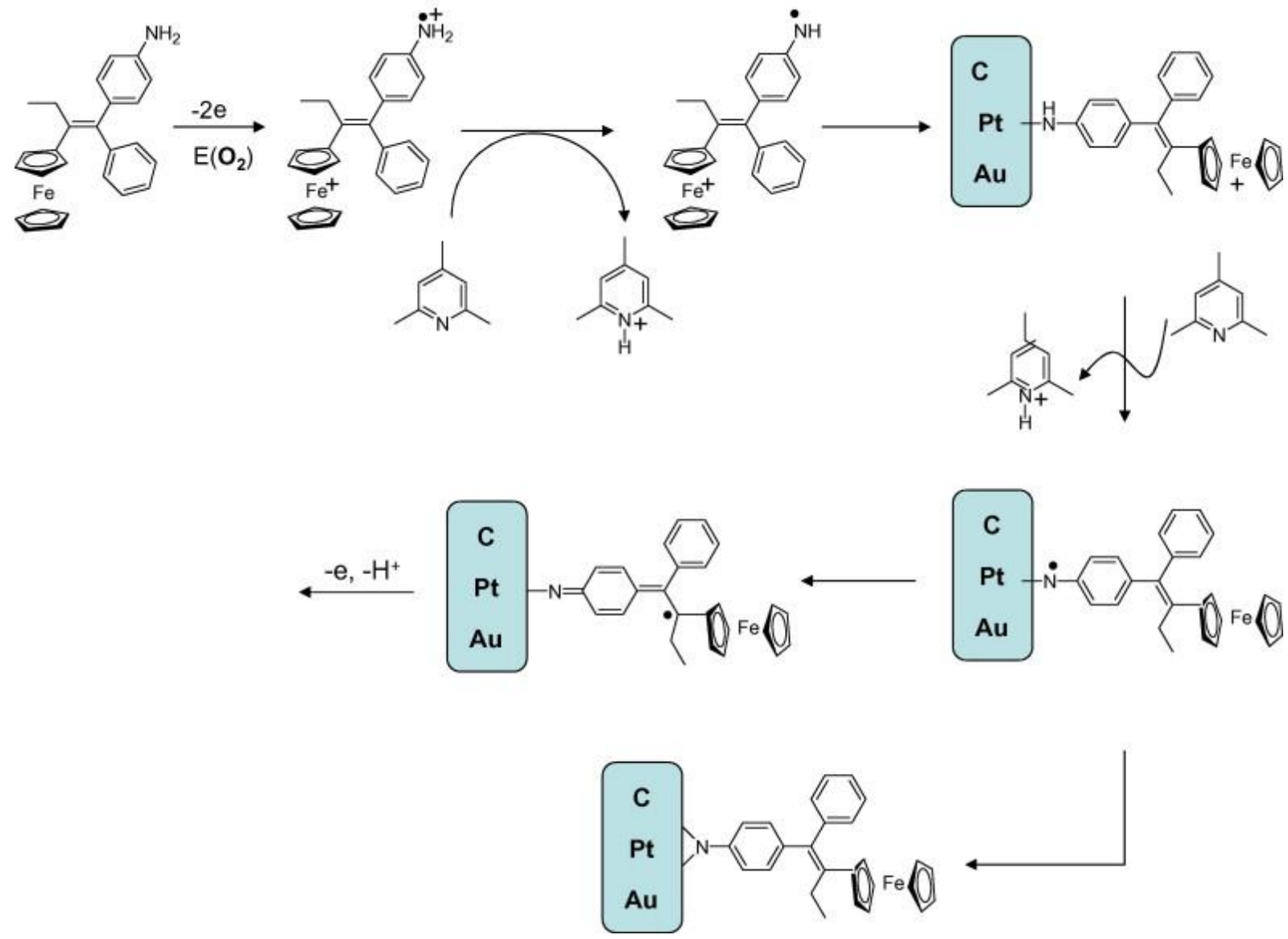

Scheme 3. Possible mechanisms for the covalent attachment of the amino-ferrocifen complex (1) via direct oxidation of the amino group.
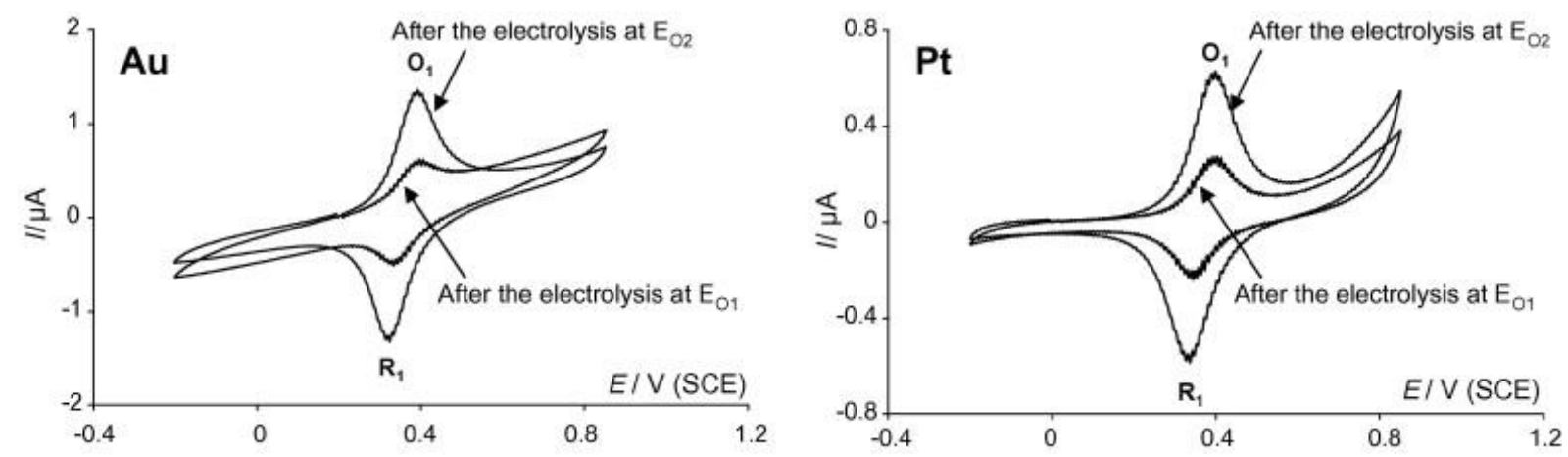

Fig. 5. Cyclic voltammograms performed in $\mathrm{MeOH}+\mathrm{LiClO}_{4}(0.1 \mathrm{M})$ with the modified working gold and platinum electrodes $(0.5 \mathrm{~mm}$ diameter $)$ obtained after the controlled-potential electrolyses at +0.70 and $+0.40 \mathrm{~V}$. 


\subsection{Attachment of the amino-ferrocene complex (1) via the oxidation of the ferrocene moiety}

As previously demonstrated, the covalent attachment of (1) can be achieved via direct oxidation of the amino group in the presence of a base. The process involves a deprotonation of the electrogenerated amino cation-radical producing an iminyl radical that may add onto the electrode surface.

On the other hand, it was demonstrated that the indirect oxidation of the amino group via a possible intra-molecular electron transfer, that would be triggered upon oxidation of the ferrocene moiety, could not be observed by cyclic voltammetry owing to the high stability of $\left(\mathbf{1}^{+}\right)$. Therefore, a $5 \mathrm{~min}$ controlled-potential electrolysis was performed at $+0.40 \mathrm{~V}$ that corresponds to the potential value at which the ferrocene moiety is oxidized into the ferrocenium species. Fig. 6 shows the cyclic voltammograms obtained before and after the electrolysis.

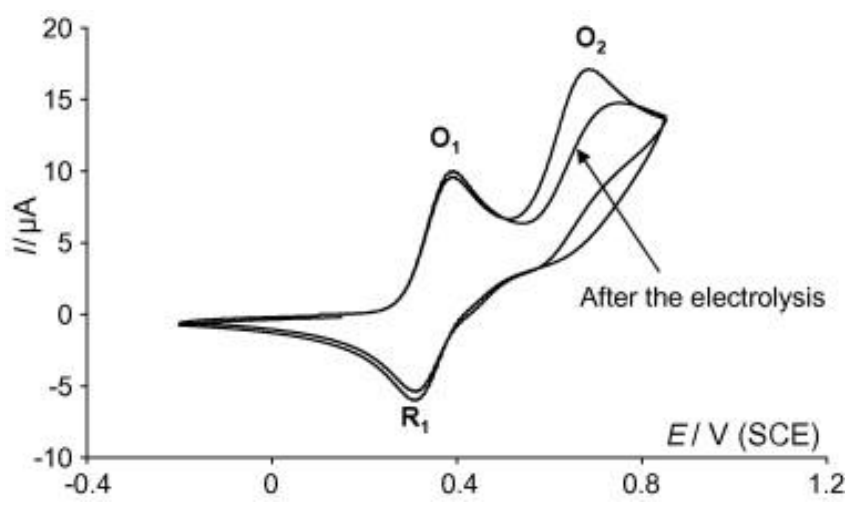

Fig. 6. Cyclic voltammograms of complex $1(5.80 \mathrm{mM})$ in $\mathrm{MeOH}+\mathrm{LiClO}_{4}(0.1 \mathrm{M})$ recorded at a glassy carbon electrode ( $1 \mathrm{~mm}$ diameter) at $100 \mathrm{mV} \mathrm{s}^{-1}$ in the presence of collidine (5 equivs.), before and after the controlledpotential electrolysis at $\mathrm{E}=+0.40 \mathrm{~V}$.

Compared to the former voltammogram (obtained after the electrolysis that was performed at $+0.70 \mathrm{~V}-$ see Fig. 3) the oxidation wave $\mathrm{O}_{2}$ was still present, but its shape was similar to that observed when the potential was repeatedly scanned (see Fig. 2) indicating a somewhat modification of the electrode surface. More importantly, the cyclic voltammogram obtained after transferring the electrode in another electrochemical cell containing only the solvent and the supporting electrolyte mixture clearly showed the attachment of complex (1) at the electrode surface (Fig. 7). 


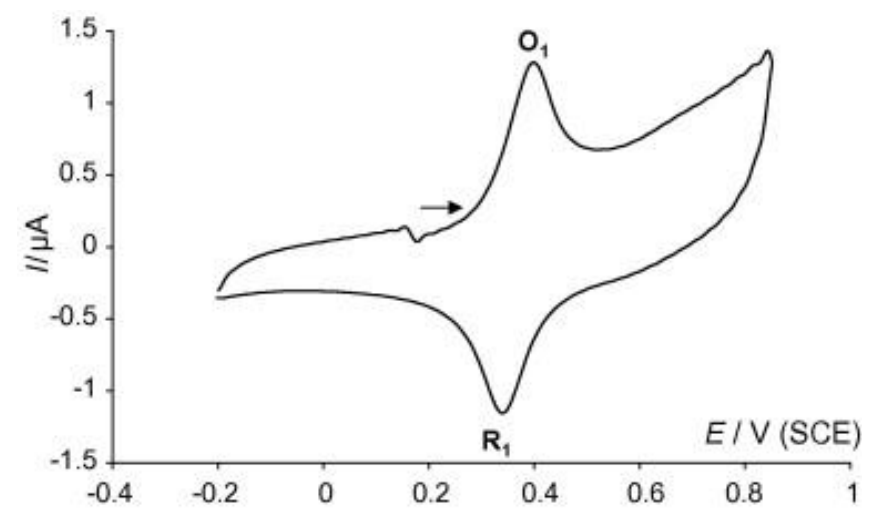

Fig. 7. Cyclic voltammogram of the modified glassy carbon electrode $(1 \mathrm{~mm}$ diameter $)$ in $\mathrm{MeOH}+\mathrm{LiClO}_{4}(0.1$ M) obtained after the controlled-potential electrolysis at $\mathrm{E}=+0.40 \mathrm{~V}$.

As expected, comparison of the cyclic voltammograms obtained after the electrolyses performed, for the same time, at $E_{\mathrm{O} 1}$ and $E_{\mathrm{O} 2}$ shows that the grafting process is more efficient in the latter case. The electrode coverage found in these cases were $2.60 \times 10^{-10}$ and $0.85 \times$ $10^{-10} \mathrm{~mol} \mathrm{\textrm {cm } ^ { - 2 }}$ before and after passing the electrode for $10 \mathrm{~min}$ in the ultrasonic bath, respectively. Here again the ultrasonic bath allows the elimination of adsorbed molecules.

More importantly, these results prove that the amino group can be oxidized thanks to an intramolecular electron transfer from the amino group to the ferrocenyl group through the conjugated $\pi$ system (Scheme 4). As expected, the cyclic voltammogram obtained from the open circuit potential showed the oxidation of the ferrocene moiety confirming the intramolecular reduction of the electrogenerated ferrocenium.

As shown in Scheme 4, the ferrocene moiety is first electrochemically oxidized, and the electron may to a small extent be delocalized over the $\pi$ system. This imparts a partial positive charge to the amino group, thus acidifying the proton, which may then be abstracted by collidine [31]. Then, an intra-molecular electron transfer can occur from the amino group to the ferrocenyl moiety, reducing thus the ferrocenium species. The resulting aminyl radical adds onto the electrode surface.

Importantly, as observed with the glassy carbon electrode, identical results were obtained on gold and platinum surfaces. Typical voltammograms obtained after electrolyses at $E_{\mathrm{O} 1}$ and transferring the electrodes in an electrochemical cell containing only the solvent and supporting electrolyte are shown in Fig. 5. 


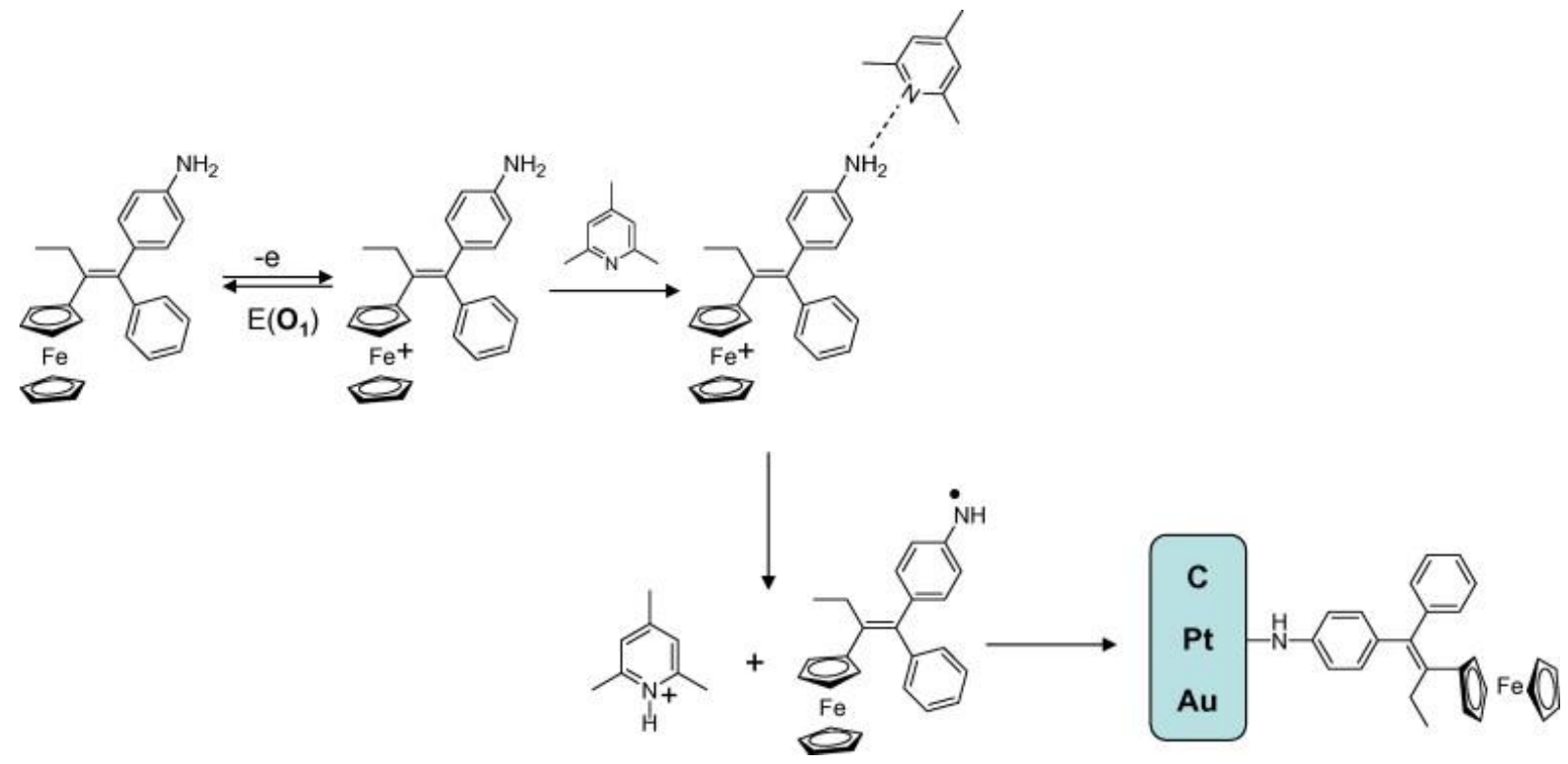

Scheme 4. Proposed mechanism for the covalent attachment of the amino-ferrocifen complex via the oxidation of the ferrocenyl group.

\section{Conclusion}

For the first time, a conjugated molecule combining both an amino and an organometallic moiety has been covalently attached to carbon and metal surfaces via the oxidation of the amino group. Importantly, it is demonstrated that oxidation of the amino group can be achieved either directly at the potential at which it is oxidized or indirectly at a lower potential corresponding to the oxidation of the ferrocene moiety. In this case, indeed, an intramolecular electron transfer takes place from the amino group to the ferrocenyl moiety. This process which is facilitated in the presence of a base leads to the production of an iminyl radical (similarly to the first case) that can add onto the electrode surface. It is proved that in both cases a strong attachment of the molecule was obtained. These results can open new opportunities for applications including molecular electronics, sensors, catalysis, and electrocatalysis. Particularly, the immobilization of amino-ferrocifen complexes can be the starting point to study the environment effects of organometallic complexes possessing therapeutic properties, in defined molecular architectures. 


\section{References}

[1] H.O. Finklea. A.J. Bard (Ed.), Electroanal. Chem., vol. 19, Dekker, New York (1996), p. 109

[2] B. Barbier, J. Pinson, G. Désarmot, M. Sanchez. J. Electrochem. Soc., 137 (1990), p. 1757

[3] R.S. Deinhammer, M. Ho, J.W. Anderegg, M.D. Porter. Langmuir, 10 (1994), p. 1306

[4] J. Pinson, F. Podvorica. Chem. Soc. Rev., 34 (2005), p. 429

[5] S. Baranton, D. Bélanger. J. Phys. Chem. B, 109 (2005), p. 24401

[6] P. Allongue, M. Delamar, B. Desbat, O. Fagebaume, R. Hitmi, J. Pinson, J.-M. Savéant. J. Am. Chem. Soc., 119 (1997), p. 201

[7] M. Delamar, R. Hitmi, J. Pinson, J.-M. Savéant. J. Am. Chem. Soc., 114 (1992), p. 5883

[8] A. Adenier, M.M. Chehimi, I. Gallardo, J. Pinson, N. Vilà. Langmuir, 20 (2004), p. 8243

[9] A.H. Holm, K.H. Vase, B. Winther-Jensen, S.U. Pedersen, K. Daasbjerg. Electrochim. Acta, 53 (2007), p. 1680

[10] M. Delamar, G. Désarmot, O. Fagebaume, R. Hitmi, J. Pinson, J.-M. Savéant. Carbon, 35 (1997), p. 801

[11] C.A. Dyke, J.M. Tour. Nano Lett., 3 (2003), p. 1215

[12] J. Wang, M.A. Firestone, O. Auciello, J.A. Carlisle. Langmuir, 20 (2004), p. 11450

[13] C. Henry de Villeneuve, J. Pinson, M.-C. Bernard, P. Allongue. J. Phys. Chem. B, 101 (1997), p. 2415

[14] P. Allongue, C. Henry de Villeneuve, G. Cherouvrier, R. Cortès, M.-C. Bernard. J. Electroanal. Chem., 550-551 (2003), p. 161 
[15] M.P. Stewart, F. Maya, D.V. Konsynkin, S.M. Dirk, J.J. Stapelton, C.L. McGuiness, D.L. Allara, J.M. Tour. J. Am. Chem. Soc., 126 (2004), p. 370

[16] A. Adenier, M.-C. Bernard, M.M. Chehimi, E. Cabet-Deliry, B. Desbat, O. Fagebaume, J. Pinson, F. Podvorica. J. Am. Chem. Soc., 123 (2001), p. 4541

[17] M.-C. Bernard, A. Chaussé, E. Cabet-Deliry, M.M. Chehimi, J. Pinson, F. Podvorica, C. Vautrin-Ul. Chem. Mater., 15 (2003), p. 3450

[18] B.L. Hurley, R.L. McCreery. J. Electrochem. Soc., 151 (2004), p. B252

[19] I. Gallardo, J. Pinson, N. Vilà. J. Phys. Chem. B, 110 (2006), p. 19521

[20] N. Vilà, M. Van Brussel, M. D’Amours, J. Marwan, C. Buess-Herman, D. Bélanger. J. Electroanal. Chem., 609 (2007), p. 85

[21] J. Liu, L. Cheng, B. Liu, S. Dong. Langmuir, 16 (2000), p. 7471

[22] O. Ghodbane, G. Chamoulaud, D. Bélanger. Electrochem. Commun., 6 (2004), p. 254

[23] G. Liu, J. Liu, T. Böcking, P.K. Eggers, J.J. Gooding. Chem. Phys., 319 (2005), p. 136

[24] S. Top, A. Vessières, G. Leclercq, J. Quivy, J. Tang, J. Vaissermann, M. Huché, G. Jaouen. Chem. Eur. J., 9 (2003), p. 5223

[25] S. Top, B. Dauer, J. Vaissermann, G. Jaouen. J. Organomet. Chem., 541 (1997), p. 355

[26] E. Hillard, A. Vessières, L. Thouin, G. Jaouen, C. Amatore. Angew. Chem. Int. Ed., 45 (2006), p. 285

[27] J.Q. Liu, M.N. Paddon-Row, J.J. Gooding. J. Phys. Chem. B, 108 (2004), p. 8460

[28] S.E. Creager, G.K. Rowe. J. Electroanal. Chem., 420 (1997), p. 291

[29] M.J. Honeychurch. Langmuir, 14 (1998), p. 6291

[30] G.K. Rowe, M.T. Carter, J.N. Richardson, R.W. Murray. Langmuir, 11 (1995), p. 1797

[31] C.J. Schlesener, C. Amatore, J.K. Kochi. J. Am. Chem. Soc., 106 (1984), p. 7472 